\title{
Development of new spectrophotometric method for estimation of tenofovir disoproxil fumarate using MBTH reagent
}

\author{
*Mannem Sri Varsha, N. Raghavendra Babu, Yenumula Padmavathi, P. Ravi Kumar \\ Department of Pharmaceutical Analysis E Quality Assurance, G. Pulla Reddy College of Pharmacy, Mehdipatnam, Hyderabad, \\ Telangana 500028, India
}

\begin{abstract}
A new simple, sensitive and specific procedure has been developed for determination of tenofovir disoproxil fumarate in bulk and pharmaceutical dosage forms using MBTH reagent. The purpose of this analytical validation procedure is to validate it by laboratory experiments to prove that the method meets the minimum standards for laboratory use. 3-methyl-2-bezothiazoline hydrazone reacts with the secondary amine group of tenofovir in the presence of oxidizing agent, ferric chloride. The resulting apple green coloured chromogen when measured spectrophotometrically in visible region (i.e., $400-800 \mathrm{~nm}$ ) shows a maximum absorbance at $626.5 \mathrm{~nm}$. This method can be successfully applied for the determination of drug content in pharmaceutical formulations. The results of analysis have been validated statistically.
\end{abstract}

Key Words: 3-methyl-2-benzothiazoline hydrazone, tenofovir disoproxil fumarate, spectrophotometric determination, ICH guidelines.

\section{INTRODUCTION}

Tenofovir disoproxil fumarate is an antiretroviral agent used in the treatment of HIV infection. It is a nucleoside reverse transcriptase inhibitor (NRTI) and it is the first nucleotide analogue used for HIV infection. It is chemically 1:1 salt of bisisopropoxyl carbonyl oxy methyl ester of tenofovir and fumaric acid. It has a chemical name of 9[(R)-2-[bis [(isopropoxycarbonyl) oxy] methyl] phosphinyl] methoxy] propyl]adeninefumarate].

Tenofovir disoproxil fumarate is a prodrug of tenofovir. Upon oral administration, it is converted to tenofovir, an acyclic nucleoside phosphonate (nucleotide) analogue of adenosine 5 '-monophosphate and blocks the reverse transcriptase enzyme that is important for HIVviral synthesis.

It has an empirical formula of $\mathrm{C}_{19} \mathrm{H}_{30} \mathrm{~N}_{5} \mathrm{O}_{10} \mathrm{P}_{2} \mathrm{C}_{4} \mathrm{H}_{4} \mathrm{O}_{4}$ with a molecular weight of $635.52 \mathrm{gm} / \mathrm{mol}$. It is a white to off-white crystalline odourless powder with a solubility of $13.4 \mathrm{mg} / \mathrm{ml}$ in distilled water and freely soluble in methanol and in DMF (IP 2007; USP 2005). Tenofovir disoproxil fumarate is given once a day as it remains in cells for longer period of time than other antiretroviral drugs.

The purpose of development and validation of analytical methods is to ensure that a suitable method for analysis of a particular analyte is specific, accurate and precise (ICH guidelines). Main purpose of this study is to validate the experimental conditions and parameters to be followed in the spectrophotometric determination of tenofovir disoproxil fumarate using MBTH reagent.

This method is based on the reaction of tenofovir disoproxil fumarate with 3-methyl-2-benzothiazolinone hydrazone hydrochloride [MBTH] reagent and ferric chloride to form green colored chromogen with absorp-

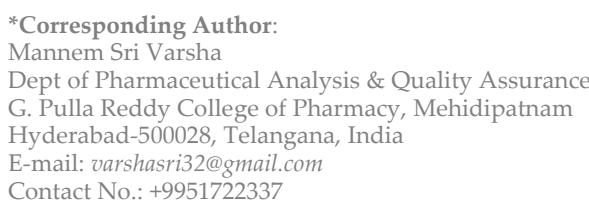

tion maximum at $626.5 \mathrm{~nm}$ and Beer's law is obeyed in the concentration range of $50-250 \mu \mathrm{g} / \mathrm{ml}$ In the present estimation of tenofovir disoproxil fumarate, MBTH loses two electrons and one proton to form an electrophlic intermediate (Revanasiddappa et al., 1999; Archana et al., 2013). The formed intermediate is highly coupling species, then reacts (or) couples with tenofovir to form a coloured chromogen (green colour) which is measured at $626.5 \mathrm{~nm}$. The scheme of reaction between drug and the colorimetric agent is shown in figure 1.

\section{MATERIALS AND METHODS}

Chemicals and reagents

Tenofovir disoproxil fumarate working standard was generous gift from Aurobindo Pharamceuticals Pvt. Ltd., Hyderabad. Ferric chloride anhydrous, Hydrochloric acid and all other chemicals were of analytical grade. Tenvir ${ }^{\circledR}$ 300 (tenofovir disoproxil fumarate, $300 \mathrm{mg}$ ), tablets were manufactured by CIPLA Pvt. Ltd., and were purchased from local market.

\section{Instrumentation}

UV-visible spectrophotometer (SCHIMADZU 1800), pH meter (Elico LI-127), Digital balance (Schimadzu BL$220 \mathrm{H})$.

Preparation of MBTH $(0.5 \% \mathrm{w} / \mathrm{v}): 50 \mathrm{mg}$ of 3-methyl-2benzothiazolinone hydrazone hydrochloride (MBTH), (Otto Kemi Chemicals, Mumbai) was dissolved in $10 \mathrm{~mL}$ water.

Preparation of $1 \%$ ferric chloride: $1 \mathrm{gm}$ of Ferric chloride anhydrous (SD Fine Chemicals Limited, Mumbai) was dissolved in $100 \mathrm{~mL} 0.1 \mathrm{~N}$ hydrochloric acid AR (SD Fine Chemicals Limited, Mumbai).

Preparation of stock solutions: Stock solution of tenofovir disoproxil fumarate was made by carefully transferring $100 \mathrm{mg}$ to $100 \mathrm{~mL}$ volumetric flask and dissolved in distilled water. From this stock solution $10 \mathrm{~mL}$ was pipette out into another $100 \mathrm{~mL}$ volumetric flask to which $1 \mathrm{~mL}$ of 
<smiles>Cn1/c(=N/N)sc2ccccc21</smiles>

MBTH

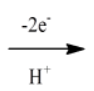<smiles></smiles>

Electrophilic Intermediate<smiles>CC(C)OC(=O)OCOP(=O)(COC(C)CN1CNc2c(N)ncnc21)OCOCO</smiles>

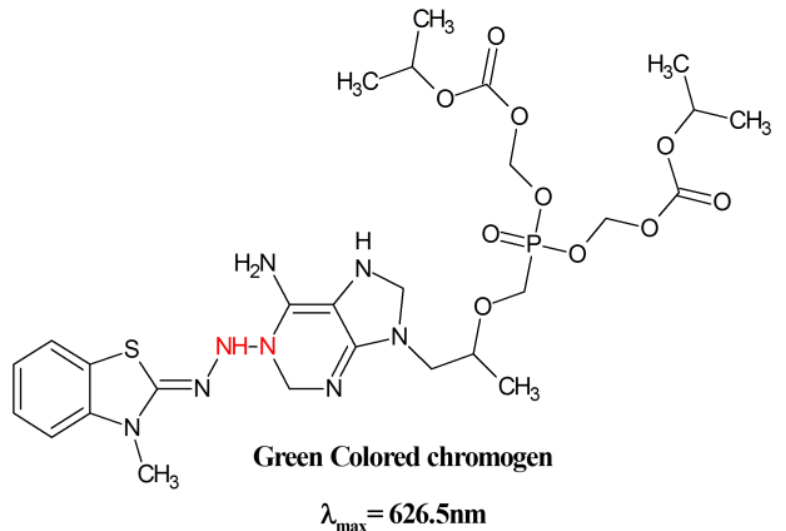

Figure 1: Proposed reaction pathway between tenofovir disoproxil fumarate (TDF) and MBTH.

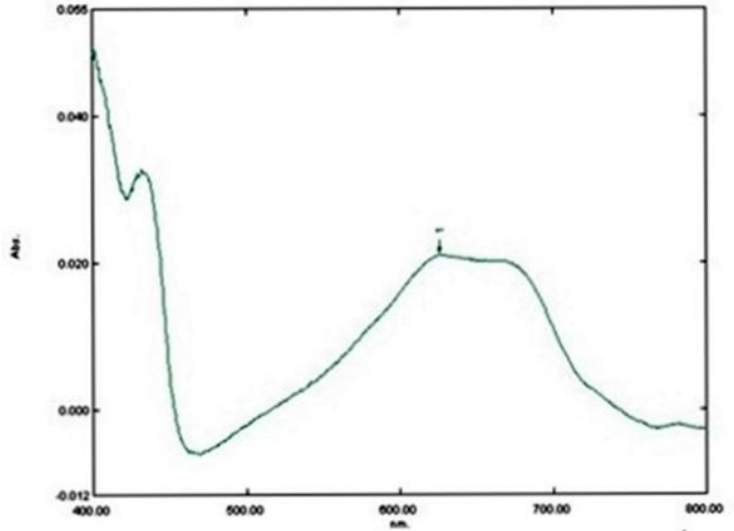

Figure 2: Spectrum of tenofovir disoproxil fumarate with MBTH Reagent.

MBTH reagent $(0.5 \% \mathrm{w} / \mathrm{v})$ and $1 \mathrm{~mL}$ of ferric chloride $(1 \%)$ solution were added and the volume was made up to $100 \mathrm{~mL}$ with distilled water to give a solution of $100 \mu \mathrm{g} / \mathrm{mL}$ solution. The absorbance of resulting coloured solution was measured against respective blank solution in visible region, i.e., $400-800 \mathrm{~nm}$ which showed a maximum absorbance at $626.5 \mathrm{~nm}$ and the spectrum is shown in figure 3 .

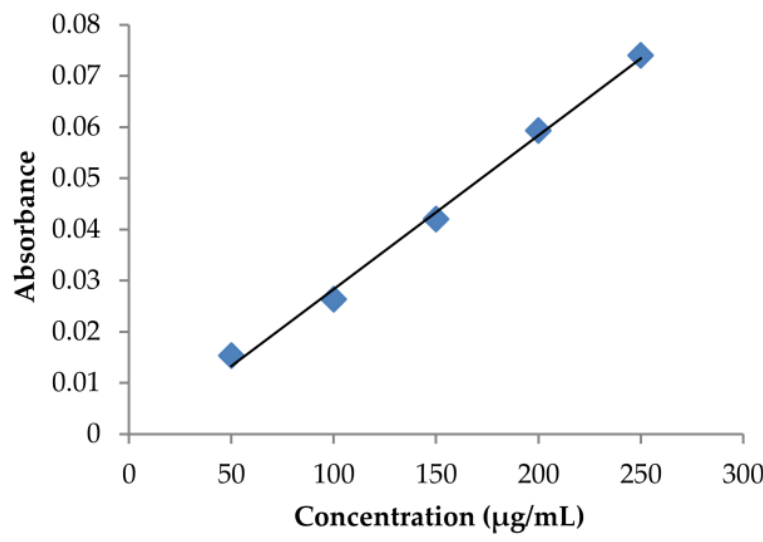

Figure 3: Calibration curve of tenofovir disoproxil fumarate with MBTH Reagent.

\section{Calibration curve $(50-250 \mu \mathrm{g} / \mathrm{ml})$ preparation}

Fresh aliquots of tenofovir ranging from $0.5-2.5 \mathrm{~mL}$ from stock solution $(1000 \mu \mathrm{g} / \mathrm{mL})$ were transferred into a series of $10 \mathrm{~mL}$ volumetric flasks to provide final concentration range of $50-250 \mu \mathrm{g} / \mathrm{mL}$. To each flask $1 \mathrm{~mL}$ of Ferric chloride $(1 \%)$ solution and $1 \mathrm{~mL}$ of $0.5 \% \mathrm{MBTH}$ reagent solution was added. The solution in each tube was made up to the mark with distilled water. The absorbance of green coloured chromogen was measured at $626.5 \mathrm{~nm}$ 
against appropriate reagent blank and the graph of absorbance against concentration was plotted as shown in the figure 3. The regression equation and coefficient correlation was given in the table 1 .

\section{Validation of the assay method}

Linearity is the ability of the analysis procedure for obtaining the results of the experiment are directly proportional to the concentration of analyte in the sample (ICH). Linearity is measured by a single measurement at different concentrations and then determined the value of the slope and intercept and also coefficient of determination.

The response of the drug was found to be linear in the investigational concentration range $50-250 \mu \mathrm{g} / \mathrm{mL}$. The calibration curve was found to be linear with an $\mathrm{r}^{2}$ value 0.9951 and regression equation was $y=0.0003 x-0.0017$. For these studies obtained $\mathrm{r}^{2}$ value was considered to be appropriate to demonstrate the linearity of the method proving the value of good linearity as approaching a value of 1 .

Limit of detection (LOD) and limit of quantitation (LOQ) are the parameters used to predict the sensitivity of proposed method as per the International Conference of Harmonization ( $\mathrm{ICH})$ guidelines for the validation of analytical procedure according to which, the following formulae were used:

$$
\begin{aligned}
& \mathrm{LOD}=3.3 \sigma / \mathrm{S} \\
& \mathrm{LOQ}=10 \sigma / \mathrm{S}
\end{aligned}
$$

Where, $\sigma=$ standard deviation of the response (intercept) $\mathrm{S}=$ slope of the calibration curve

The mean of the slope and standard deviation of response were obtained after plotting three calibration curves.

The optimum conditions such as Beer's law limits, molar absorptivity, Sandell's sensitivity and other regression characteristics like slope $(\mathrm{m})$, intercept (c), correlation coefficient were calculated and given in table 2 .

Accuracy is the closeness of test results between the results obtained with the true value (true value) or the value of the reference. It describes the systematic error of the measurement results. Accuracy for drug substance was determined on samples of drug solutions at varying concentration levels in the range of $80 \%-120 \%(120 \mu \mathrm{g} / \mathrm{mL}$, $150 \mu \mathrm{g} / \mathrm{mL}, 180 \mu \mathrm{g} / \mathrm{mL}$ ) by analyzing three replicates of each sample as a batch in a single assay. The \%RSD was calculated and reported in table 3 . To study the accuracy of drug product, 10 tablets (Tenvir-300) were weighed, powdered and estimation was carried out. Recovery studies were carried out by adding known amount of standard drug solution $(120,150,180 \mu \mathrm{g} / \mathrm{mL})$ to the sample solution $(150 \mu \mathrm{g} / \mathrm{mL})$. The $\%$ recovery was calculated and reported in the table 4 .

The obtained values of recovery studies were in the range of $98.7-103.6 \%$ which indicates that the proposed method is accurate. ICH demands that 'a good accuracy value' should be in the range of $98-102 \%$ of the true value.

Precision of an analytical method is the degree of agreement among individual test results, when the method is applied repeatedly to multiple samplings of homogeneous sample. It provides an indication of random errors results and expressed as Relative Standard Deviation (\%RSD). Repeatability assessment of an analytical method is performed by analyzing six replicates of single concentration that is $150 \mu \mathrm{g} / \mathrm{mL}$. Absorbance of
Table 1: Calibration curve data.

\begin{tabular}{ccc}
\hline Sl. no & Concentration $(\boldsymbol{\mu g} / \mathbf{m L})$ & Absorbance $(\mathbf{n}=\mathbf{3})$ \\
\hline 1 & 50 & 0.015 \\
2 & 100 & 0.026 \\
3 & 150 & 0.046 \\
4 & 200 & 0.06 \\
5 & 250 & 0.076 \\
\hline
\end{tabular}

Table 2: Optimum conditions and spectral data.

\begin{tabular}{|l|l|}
\hline$\lambda$ max & $626.5 \mathrm{~nm}$ \\
Beer's law range & $50-250 \mu \mathrm{g} / \mathrm{mL}$ \\
Sandell's sensitivity $\left(\mu \mathrm{g} / \mathrm{cm}^{2} / 0.001\right.$ & 3.33 \\
absorbance units) & $1.65 \times 108$ \\
Molar absorptivity $($ litre/moles $/ \mathrm{cm})$ & 6.87 \\
Limit of detection $(\mu \mathrm{g} / \mathrm{mL})$ & 20.8 \\
Limit of quantification $(\mu \mathrm{g} / \mathrm{mL})$ & $\mathrm{y}=0.0003 \mathrm{x}-0.0017$ \\
Regression equation $(\mathrm{y})$ & 0.0003 \\
Slope & -0.0017 \\
Intercept & 0.9951 \\
Correlation coefficient $\left(\mathrm{r}^{2}\right)$ & $6.24 \times 10^{-4}$ \\
Standard deviation of Intercept & \\
\hline
\end{tabular}

Table 3: Accuracy data of tenofovir disoproxil fumarate (pure drug) at $626.5 \mathrm{~nm}$ using MBTH Reagent.

\begin{tabular}{cccc}
\hline Sl. no & $\begin{array}{c}\text { Concentration } \\
(\mu \mathrm{g} / \mathrm{mL})\end{array}$ & $\begin{array}{c}\text { Mean } \pm \text { Standard } \\
\text { deviation }(\mathbf{n}=\mathbf{3})\end{array}$ & \%RSD \\
\hline 1 & 120 & $120 \pm 1$ & 0.83 \\
2 & 150 & $150.3 \pm 1.5$ & 0.99 \\
3 & 180 & $180.3 \pm 1.6$ & 0.89 \\
\hline
\end{tabular}

Table 4: Accuracy data of tenofovir disoproxil fumarate (drug product) at $626.5 \mathrm{~nm}$ using MBTH Reagent.

\begin{tabular}{ccccc}
\hline $\begin{array}{c}\text { Tablet } \\
\text { used }\end{array}$ & $\begin{array}{c}\text { Amount of } \\
\text { sample } \\
\text { added } \\
(\boldsymbol{\mu g} / \mathbf{m L})\end{array}$ & $\begin{array}{c}\text { Amount of } \\
\text { standard } \\
\text { added } \\
(\boldsymbol{\mu g} / \mathbf{m L})\end{array}$ & $\begin{array}{c}\text { Amount } \\
\text { recovered } \\
(\boldsymbol{\mu g} / \mathbf{m L})\end{array}$ & $\begin{array}{c}\text { \%Recovery } \pm \\
\text { Standard } \\
\text { Deviation }(\mathbf{n}=3)\end{array}$ \\
\hline \multirow{3}{*}{ Tenvir } & 150 & 120 & 269.86 & $98.87 \pm 1.064$ \\
& 150 & 150 & 298.33 & $98.88 \pm 1.2$ \\
& 150 & 180 & 336.33 & $101.9 \pm 1.28$ \\
\hline
\end{tabular}

Table 5: Repeatability data of tenofovir disoproxil fumarate at $626.5 \mathrm{~nm}$ using MBTH reagent.

\begin{tabular}{ccccc}
\hline $\begin{array}{c}\text { S1. } \\
\text { no }\end{array}$ & $\begin{array}{c}\text { Concentration } \\
(\mu \mathrm{g} / \mathrm{mL})\end{array}$ & Absorbance & $\begin{array}{c}\text { Mean } \pm \text { Standard } \\
\text { deviation }\end{array}$ & \%RSD \\
\hline 1 & & 0.0370 & & \\
2 & & 0.0380 & & \\
3 & 150 & 0.0382 & $0.0379 \pm 0.000456$ & 1.203 \\
4 & & 0.0379 & & \\
5 & & 0.0381 & & \\
6 & & 0.0382 & & \\
\hline
\end{tabular}

samples is recorded at $626.5 \mathrm{~nm}$. The \% relative standard deviation (RSD) was calculated and reported in table 5.

Variations of results within the same day (intraday) and variation of results between days (inter day) were analyzed. The intra-assay precision of the proposed method was determined on samples of drug solutions at varying concentration levels $(150 \mu \mathrm{g} / \mathrm{mL}, 200 \mu \mathrm{g} / \mathrm{mL}$, $250 \mu \mathrm{g} / \mathrm{mL}$ ) by analyzing three replicates of each sample as a batch in a single assay run at $626.5 \mathrm{~nm}$. The Inter-assay 
Table 6: Intra-day and Inter day Precision data of tenofovir disoproxil fumarate at 626.5nm using MBTH Reagent.

\begin{tabular}{cccccc}
\hline S1. no & Concentration $(\mu \mathrm{g} / \mathbf{m L})$ & $\begin{array}{c}\text { Intraday absorbance Mean } \\
\pm \text { Standard deviation(n=3) }\end{array}$ & \%RSD & $\begin{array}{c}\text { Interday absorbance } \\
\text { Mean } \pm \text { Standard Deviation(n=3) }\end{array}$ & \%RSD \\
\hline 1 & 150 & $0.0393 \pm 0.001155$ & 1.92 & $0.0383 \pm 0.000703$ & 1.85 \\
2 & 200 & $0.0593 \pm 0.001155$ & 1.94 & $0.059 \pm 0.001158$ & 1.96 \\
3 & 250 & $0.074 \pm 0.0014504$ & 1.96 & $0.075 \pm 0.001485$ & 1.98 \\
\hline
\end{tabular}

Table 7: Ruggedness results of Tenvir $300 \mathrm{mg}$ tablet at $626.5 \mathrm{~nm}$ using MBTH Reagent.

\begin{tabular}{ccc}
\hline \multirow{2}{*}{ Replicates } & \multicolumn{2}{c}{ \% Label content } \\
\cline { 2 - 3 } & Analyst-I & Analyst-II \\
\hline 1 & 104 & 101 \\
2 & 101 & 103 \\
3 & 102 & 100 \\
4 & 99.8 & 99.9 \\
5 & 100 & 102 \\
6 & 101 & 104 \\
Average & 101.3 & 101.65 \\
SD & 1.5427 & 1.6537 \\
\%RSD & 1.523 & 1.627 \\
\hline
\end{tabular}

precision was determined by analyzing the same samples $(150 \mu \mathrm{g} / \mathrm{mL}, 200 \mu \mathrm{g} / \mathrm{mL}, 250 \mu \mathrm{g} / \mathrm{mL})$ in three consecutive days at $626.5 \mathrm{~nm}$. The $\%$ RSD was calculated and results were in table 6 .

Ruggedness of an analytical method is the degree of reproducibility of test results obtained by analysis of same samples under a variety of conditions such as different laboratories, different analysts, different instruments, different days etc. Ruggedness is normally expressed as lack of influence on the test results of operational and environmental variables of analytical method. Ruggedness is a measure of reproducibility of test results under the variation in normally expected from laboratory to laboratory and analyst to analyst.

Ten tablets were weighed and finely powdered. The powder equivalent to $100 \mathrm{mg}$ was weighed and transferred to $100 \mathrm{~mL}$ volumetric flask containing $25 \mathrm{~mL}$ methanol and sonicated for 30 minutes. The solution was centrifuged at $2500 \mathrm{rpm}$ for 15 minutes. From the above solution $(1000 \mu \mathrm{g} / \mathrm{ml}) 1.5 \mathrm{~mL}$ of sample was pipetted into $10 \mathrm{~mL}$ graduated tube followed by addition of $1 \mathrm{~mL}$ of MBTH reagent $(0.5 \% \mathrm{w} / \mathrm{v})$ and $1 \mathrm{~mL}$ of Ferric chloride solution $(1 \%)$ and solution was made to $10 \mathrm{~mL}$ using distilled water. The absorbance of resulting green coloured solution was measured at $626.5 \mathrm{~nm}$ against appropriate reagent blank. The \% label content was reported to which \% relative standard deviation (RSD) was calculated. The results obtained were shown in table 7.

\footnotetext{
Application of the method for estimation of tenofovir disoproxil fumarate in tablets using MBTH Reagent Twenty tablets of tenofovir disoproxil fumarate (Tenvir manufactured by Cipla Ltd., Goa, India, contains 300mg of tenofovir disoproxil fumarate) were weighed and finely powdered. The powder equivalent to $100 \mathrm{mg}$ was weighed and transferred to $100 \mathrm{~mL}$ volumetric flask containing $25 \mathrm{~mL}$ methanol and sonicated for 30 minutes. The flask was shaken and volume was made up to mark with methanol to obtain a solution of $1000 \mu \mathrm{g} / \mathrm{mL}$. The solution was centrifuged at $2500 \mathrm{rpm}$ for 15 minutes.

From the above solution $(1000 \mu \mathrm{g} / \mathrm{ml}), 1.5 \mathrm{~mL}$ of sample was pipetted into $10 \mathrm{~mL}$ graduated tube followed by addition of $1 \mathrm{~mL}$ of MBTH reagent $(0.5 \% \mathrm{w} / \mathrm{v})$ and $1 \mathrm{~mL}$ of
}

Ferric chloride solution (1\%) and solution was made to $10 \mathrm{~mL}$ using distilled water. The absorbance of resulting green colored solution was measured at $626.5 \mathrm{~nm}$ against appropriate reagent blank.

\section{RESULTS AND DISCUSSION}

The analytical method development and validation for the tenofovir disoproxil fumarate using $\mathrm{MBTH}$ reagent was carried out. The linearity calibration curve (figure 2) shows linear response over the range of concentration used. The precision data shows that the reproducibility of the assay procedure was satisfactory and the accuracy of the method was determined by recovery studies (table 1-7).

The developed and validated method was successfully applied for estimation of drug in formulation. The results (308.21mg, $102.73 \%$ of label claimed) were found to be well within the acceptable limits of $90-110 \%$ (IP).

\section{CONCLUSION}

From the above discussion it can be concluded that all validation parameters (precision, accuracy, linearity) met the predetermined acceptance criteria and the developed spectrophotometric method can be applied for routine analysis of tenofovir disoproxil fumarate and its dosage forms.

\section{REFERENCES}

Archana S, Naga Prasanna Y, Pavitra P, Santhi Krupa D, Hema Sri M. (2013) Development and Validation of Spectrophotometric method for determination of Risperidone by MBTH. International Journal of Pharmaceutical Sciences and Research, 4(3): 1116-1119.

ICH, Q2 Validation of Analytical Procedures: Text and Methodology. International Conference on Harmonization of Technical Requirement for Registration of Pharmaceuticals for Human Use, ICH harmonized Tripartite Guideline, Nov 2005.

Indian Pharmacopoeia (2007) Volume 3, Indian Pharmacopoeial Commision, Ghaziabad: 1783-1784.

Revanasiddappa H.D, Manju B (1999), Spectrophotometric determination of antidepressant drugs using 3-methylbenzothiazoline-2-one hydrazone. European journal of Pharmaceutical Sciences; 9(2): 221-225. [DOI]

Sawicki E, Hauser TR, Stanley TW, Elbert W (1961) The 3-methyl-2benzothiazoline hydrazone Sensitive New Methods for detection, rapid estimation and determination of aliphatic aldehydes. Analytical Chemistry, 33(10): 93-96.

United States Pharmacopoeia (2005), 28th edition, Published by The US Pharmacopoeial Convention,Inc., Rockille MD, 2749-2751. 